\title{
História da Educação Científica: revisando aspectos e construindo perspectivas
}

\author{
History of Scientific Education: reviewing aspects and building \\ perspectives
}

\section{Historia de la Educación Científica: revisando aspectos y construyendo perspectivas}

Lucas de Sousa Ribeiro; ${ }^{1}$ Maria Danielle Araújo Mota²; Raquel Crosara Maia Leite $^{3}$

\section{RESUMO}

Esta revisão de literatura tem como objeto de estudo a história da Educação Científica desde meados do século XX até o começo do século XXI (1950 - 2018) a partir de três objetivos específicos: compreender os fatores político-econômicos que interferiram no desenvolvimento da Educação Científica, analisar os fatores culturais e pedagógicos que permearam essa história, e discutir os caminhos que a Educação Científica tem para o século XXI. Constitui, portanto, uma pesquisa bibliográfica de cunho histórico, cujas outras pesquisas são consideradas fontes secundárias. Observamos uma convergência dos autores para compreensão de que as concepções de ciência e ensino de ciências positivistas, ainda hegemônicos, decorrem de uma história marcada por fortes influências políticas, econômicas, culturais e pedagógicas estadunidenses. Contudo, pesquisas recentes trazem novas contribuições sobre o papel da ciência e do ensino de ciências na era da informação, o que pode significar uma mudança de perspectivas e uma nova forma de se construir a Educação Científica do século XXI.

Palavras-chave: Educação Científica; Revisão de Literatura; História da Educação Científica.

\begin{abstract}
This literature review has as its object of study the history of Scientific Education from the 20th century until the beginning of the 21st century (1950 - 2018) based on three specific objectives: to understand the political and economic factors that interfered in the development of Science Education, factors the cultural and pedagogical factors that permeated this history, and discuss the paths that Scientific Education has for the 21st century. It is, therefore, a bibliographic research of a historical nature, whose other researches are considered direct sources of investigation. We observe a convergence of the authors to understand that the positivist science and science conceptions, still hegemonic, result from a history marked by strong American political, economic, cultural and pedagogical influences. However, recent research brings new contributions on the role of science and science teaching in the information age, which can mean a change in perspectives and a new way of building 21st century science education.
\end{abstract}

Keywords: Science Education; Literature review; History of scientific education.

1 Licenciado em Ciências Biológicas e Mestre em Educação. Professor de Educação Básica do Município de Fortaleza/CE e do Governo do Estado do Ceará. E-mail: lucas.ribeiro.bio@gmail.com

${ }^{2}$ Doutora e Mestre em Educação. Professora da Universidade Federal de Alagoas (UFAL), Campus A.C Simões. E-mail: danielle.araujo@icbs.ufal.br

${ }^{3}$ Doutora e Mestre em Educação. Professora do Programa de Pós-Graduação em Educação Brasileira e do Mestrado Profissional em Ensino de Ciências e Matemática (ENCIMA). E-mail: raquelcrosara@ufc.br 


\section{RESUMEN}

Esta revisión de la literatura tiene como objeto de estudio la historia de la Educación Científica desde el siglo XX hasta principios del siglo XXI (1950 - 2018) a partir de tres objetivos específicos: comprender los factores políticos y económicos que interfirieron en el desarrollo de la Educación Científica, factores culturales y pedagógicos que impregnaron esta historia, y discutir los caminos que tiene la Educación Científica para el siglo XXI. Se trata, por tanto, de una investigación bibliográfica de carácter histórico, cuyas otras investigaciones se consideran fuentes directas de investigación. Observamos una convergencia de los autores para entender que la ciencia positivista y las concepciones científicas, aún hegemónicas, resultan de una historia marcada por fuertes influencias políticas, económicas, culturales y pedagógicas estadounidenses. Sin embargo, investigaciones recientes aportan nuevas contribuciones sobre el papel de la ciencia y la enseñanza de las ciencias en la era de la información, lo que puede significar un cambio de perspectivas y una nueva forma de construir la educación científica del siglo XXI.

Palabras clave: Educación Científica; Revisión de literatura; Historia de la educación científica.

\section{INTRODUÇÃO}

Avanços científicos e tecnológicos, como smartphones, tablets, smartwatches, nanotecnologias, tem provocado alterações no modo de viver de sociedades humanas, em pouco tempo. Esses avanços científicos e tecnológicos associados a essas mudanças na sociedade, porém, parecem ainda não estar incorporadas nas práticas pedagógicas das aulas de ciências.

Segundo Silva et al (2016), as concepções positivista e empirista de ciência, ou seja, a ciência compreendida como um conhecimento fragmentado e individualista, continuam sendo as concepções mais recorrentes nas aulas de ciências da natureza. Contudo essa concepção de ciência pode dificultar a compreensão das diferentes formas de construir o conhecimento científico.

Para Leite (2004), o estudo da Epistemologia e da História da Ciência pode ser um caminho a ser seguido na superação dessa concepção positivista, empirista e estática da ciência. Desta forma, buscamos organizar o presente texto de forma contextualizada historicamente, compreendendo que nenhuma categoria é estática e dada como verdade, mas que foi construída e que pode, a qualquer momento, ser revisada.

Esta revisão de literatura tem como objetivo discutir a história da Educação Científica desde meados do século XX até o começo do século XXI (1920 - 2018), a partir do levantamento realizado, iniciado em 2017 e finalizado em 2020, em três bases de dados': No site da ABRAPEC (Associação Brasileira de Pesquisa em Educação em Ciências), onde buscamos nos Atas dos cinco últimos ENPEC (Encontro Nacional de Pesquisas em Educação em Ciências), evento de referência para área de ensino de ciências no país; na Biblioteca Digital Brasileira de Teses e Dissertações (BDTD), onde encontramos produções defendidas no país e no exterior; e no Portal de Periódicos da Coordenação de Aperfeiçoamento de Pessoal de Nível Superior (Portal dos Periódicos CAPES) - cujo acervo de trabalhos aproxima-se de 37 mil títulos. Foram utilizados alguns descritores os de busca: educação científica, ensino de ciências, currículo de ciências. No site da BDTD utilizamos, ainda, operadores lógicos boleanosii para restringir a sequência lógica dos descritores.

Ao longo de nosso levantamento, nas três bases de dados, encontramos 1.598 títulos, dos quais muitos não eram específicos ao ensino de ciências, mas ao currículo de ciências sociais ou de ciências humanas, ou de outras áreas diferentes das ciências naturais. Após a triagem dos títulos, chegamos a 138 publicações, das quais algumas estavam repetidas, ou seja, havíamos encontrado a mesma 
publicação em mais de uma base da dados, chegando ao novo quantitativo de 84 títulos, dos quais passaram pela leitura completa dos resumos, a fim de garantir uma maior proximidade com a área de Educação Científica. Por fim, restaram 30 textos que foram escolhidos para compor essa revisão, disponíveis no quadro 1 com a lista dos textos selecionados, abaixo:

Quadro 1: Lista de Textos Selecionados (Base de dados - Título - Tipo).

\begin{tabular}{|c|c|c|}
\hline BASE & TÍTULO & TIPO \\
\hline BDTD & $\begin{array}{l}\text { FENNER, Roniere dos Santos; PINO, Jose Claudio del. Currículo de ciências da } \\
\text { natureza: o processo de reconstrução do projeto político-pedagógico } \\
\text { em escola pública de ensino médio e a formação de professores. } 2014 . \\
145 \text { f. Tese (Doutorado) - Curso de Programa de Pós-graduação em Educação } \\
\text { em Ciências: Química da Vida e Saúde, Instituto de Ciências Básicas da Saúde, } \\
\text { Universidade Federal do Rio Grande do Sul, Porto Alegre, 2014. Disponível em: } \\
\text { <http://www.lume.ufrgs.br/handle/10183/109721>. Acesso em: } 02 \text { abr. } 2017\end{array}$ & Tese \\
\hline BDTD & 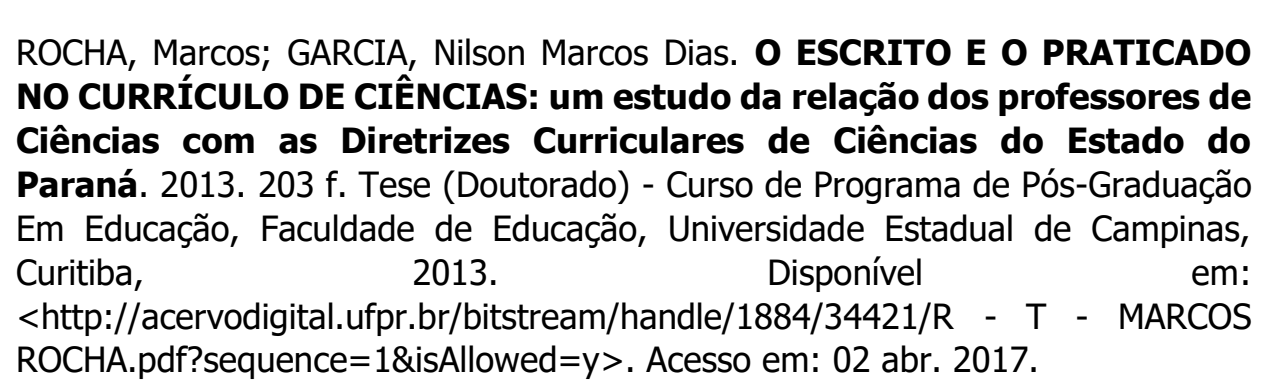 & Tese \\
\hline BDTD & $\begin{array}{l}\text { CARVALHO FILHO, Roper Pires de. Currículo e ensino de história em uma } \\
\text { escola da rede municipal de São Paulo: entre prescrições e práticas } \\
\text { [doi:10.11606/T.48.2015.tde-27102015-091800]. São Paulo: Faculdade de } \\
\text { Educação, Universidade de São Paulo, 2015. Tese de Doutorado em Educação. } \\
\text { [acesso 2017-04-02]. }\end{array}$ & Tese \\
\hline BDTD & $\begin{array}{l}\text { DOURADO, Sandra Maria de Araújo; ZANCUL, Maria Cristina de Senzi; VIVEIRO, } \\
\text { Alessandra Aparecida. Ensino de ciências no 50 ano do ensino } \\
\text { fundamental: o currículo modelado e aspectos do currículo em ação. } \\
2015.133 \text { f. Dissertação (Mestrado) - Curso de Programa de Pós-graduação em } \\
\text { Educação Escolar da Faculdade de Ciências e Letras, Unesp, Araraquara, } 2015 . \\
\text { Disponível } \\
\text { <https://repositorio.unesp.br/bitstream/handle/11449/124144/000828984.pdf?s } \\
\text { equence=1\&isAllowed }=y>\text {. Acesso em: } 02 \text { abr. } 2017 .\end{array}$ & Dissertação \\
\hline BDTD & $\begin{array}{l}\text { MARGIOTTI, Marina da Silva; MURANAKA, Maria Aparecida Segatto. } \\
\text { EXPECTATIVAS DE APRENDIZAGEM DIANTE DA PROGRESSÃO } \\
\text { CONTINUADA. 2010. } 184 \mathrm{f} \text {. Dissertação (Mestrado) - Curso de Programa de } \\
\text { Pós-graduação em Educação, Unesp, Rio Claro, 2010. Disponível em: } \\
\text { <https://repositorio.unesp.br/bitstream/handle/11449/90216/margiotti_ms_me } \\
\text { _rcla.pdf?sequence=1\&isAllowed=y>. Acesso em: } 02 \text { abr. } 2017\end{array}$ & Dissertação \\
\hline BDTD & $\begin{array}{l}\text { CAMPELO, Flávia de Nobre. O ENSINO DE CIÊNCIAS NO } 9^{\circ} \text { ANO DO ENSINO } \\
\text { FUNDAMENTAL: UMA PROPOSIÇÃO DE DESFRAGMENTAÇÃO DO } \\
\text { CURRÍCULO. } 2015.152 \text { f. Dissertação (Mestrado) - Curso de Programa de } \\
\text { Pósgraduação em Ensino de Ciências e Matemática, Faculdade de Educação, } \\
\text { Universidade Federal de Pelotas, Pelotas, } 2015 . \quad \text { Disponível em: } \\
\text { <http://repositorio.ufpel.edu.br/handle/ri/2777>. Acesso em: } 02 \text { abr. } 2017\end{array}$ & Dissertação \\
\hline BDTD & $\begin{array}{l}\text { RIBEIRO, Ednéia Castilho; MICARELLO, Hilda Aparecida Linhares da Silva. } \\
\text { Proposta curricular da rede municipal de Juiz de Fora: um olhar para a }\end{array}$ & Dissertação \\
\hline
\end{tabular}




\begin{tabular}{|c|c|c|}
\hline & $\begin{array}{l}\text { transição da educação infantil ao ensino fundamental. 2014. } 127 \text { f. } \\
\text { Dissertação (Mestrado) - Curso de Programa de Pós-graduação em Educação, } \\
\text { Faculdade de Educação, Universidade Federal de Juiz de Fora, Juiz de Fora, } 2014 . \\
\text { Disponível } \\
\text { em: } \\
\text { <https://repositorio.ufjf.br/jspui/bitstream/ufjf/758/1/edineiacastilhoribeiro.pdf } \\
\text { >. Acesso em: } 02 \text { abr. 2017. }\end{array}$ & \\
\hline BDTD & $\begin{array}{l}\text { SILVA, Andréia Vaz. A elaboração da proposta curricular para os anos } \\
\text { iniciais do ensino fundamental na rede pública municipal de Limeira } \\
\text { durante o ano de 2013: uma análise sobre os contextos de influência e } \\
\text { produção de texto. 2014. } 198 \mathrm{f} \text {. Dissertação (Mestrado) - Curso de Mestrado } \\
\text { em Gestão e Avaliação em Educação Pública, Universidade Federal de Juiz de } \\
\begin{array}{llll}\text { Fora, } & \text { Juiz } \quad \text { de } \quad \text { Fora, } & 2014 . & \text { Disponível } \\
\text { <https://repositorio.ufjf.br/jspui/handle/ufjf/629>. Acesso em: } 02 \text { abr. } 2017 .\end{array}\end{array}$ & Dissertação \\
\hline BDTD & $\begin{array}{l}\text { APPOLINÁRIO, Daniele Lenharo. Provinha Brasil: repercussões nas práticas } \\
\text { curriculares da educação infantil. 2015. } 160 \mathrm{f} \text {. Dissertação (Mestrado em } \\
\text { Educação) - Pontifícia Universidade Católica de Campinas, Campinas, } 2015 . \\
\begin{array}{l}\text { Disponível } \quad \text { em: } \quad<\quad \text { http://tede.bibliotecadigital.puc- } \\
\text { campinas.edu.br:8080/jspui/handle/tede/743>. Acesso em: } 02 \text { abr. } 2017 .\end{array}\end{array}$ & Dissertação \\
\hline $\begin{array}{c}\text { Periódicos } \\
\text { Capes }\end{array}$ & $\begin{array}{l}\text { Palma, Lisiane Celia, Alves, Nilo Barcelos, \& Silva, Tânia Nunes da. (2013). } \\
\text { Educação para a sustentabilidade: a construção de caminhos no } \\
\text { Instituto Federal de Educação, Ciência e Tecnologia do Rio Grande do } \\
\text { Sul (IFRS). RAM. Revista de Administração Mackenzie, 14(3), 83-118. Disponível } \\
\text { em: < https://dx.doi.org/10.1590/S1678-69712013000300005>. Acesso em: } 02 \\
\text { abr. 2017. }\end{array}$ & Artigo \\
\hline $\begin{array}{l}\text { Periódicos } \\
\text { Capes }\end{array}$ & 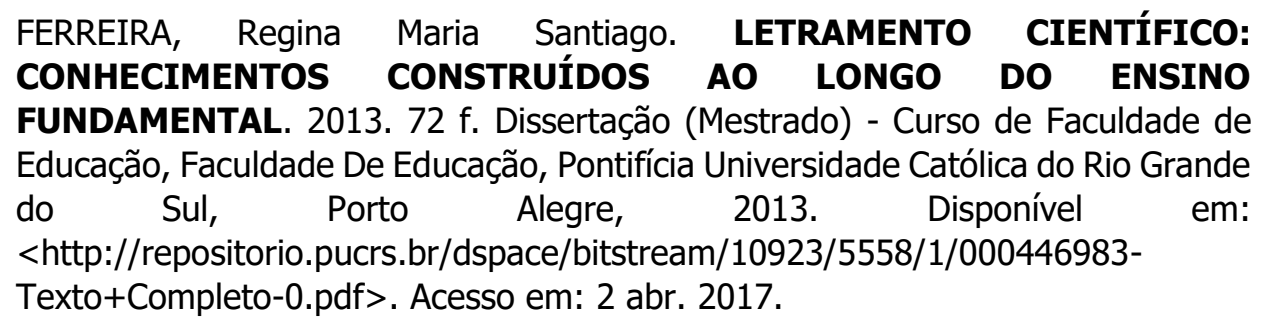 & Dissertação \\
\hline $\begin{array}{l}\text { Periódicos } \\
\text { Capes }\end{array}$ & 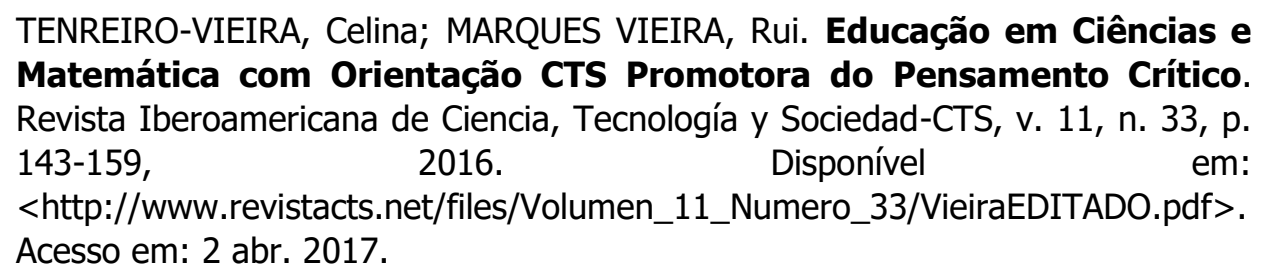 & Artigo \\
\hline $\begin{array}{c}\text { Periódicos } \\
\text { Capes }\end{array}$ & $\begin{array}{l}\text { ARAGÃO, A. M. F. (2012). Ciência e reflexividade: considerações a partir } \\
\text { de um projeto formativo-investigativo.Magis, Revista Internacional de } \\
\text { Investigación en Educación, } 5(10), 17-29 \text {. Disponível em: } \\
\text { <http://www.redalyc.org/articulo.oa?id=281024896002>. Acesso em: } 2 \text { abr. } \\
\text { 2017. }\end{array}$ & Artigo \\
\hline $\begin{array}{c}\text { Periódicos } \\
\text { Capes }\end{array}$ & $\begin{array}{l}\text { TENÓRIO, Kadja Michele Ramos et all. Propostas curriculares para Educação } \\
\text { Física em Pernambuco: entendimentos acerca do esporte. Revista } \\
\text { Brasileira de Ciências do Esporte, v. 37, n. 3, p. 280-288, 2015. Disponível em: < } \\
\text { http://www.sciencedirect.com/science/article/pii/S0101328915000608>. Acesso } \\
\text { em: } 2 \text { abr. 2017. }\end{array}$ & Artigo \\
\hline $\begin{array}{c}\text { Periódicos } \\
\text { Capes }\end{array}$ & $\begin{array}{l}\text { Marques, Sandra Mari Kaneko. Relação poder-saber e formas de resistência } \\
\text { em documentos educacionais governamentais sobre ensino de língua } \\
\text { estrangeira.Alfa: Revista de Linguística (São José do Rio Preto). Universidade } \\
\text { Estadual Paulista Júlio de Mesquita Filho, v. } 56, \mathrm{n} .1 \text {, p. } 271-292,2012 \text {. Disponível } \\
\text { em: <http://hdl.handle.net/11449/27058>. Acesso em: } 2 \text { abr. } 2017 \text {. }\end{array}$ & Artigo \\
\hline
\end{tabular}




\begin{tabular}{|c|c|c|}
\hline $\begin{array}{c}\text { Periódicos } \\
\text { Capes }\end{array}$ & $\begin{array}{l}\text { OLIVEIRA, THAIS BENETTI DE; CALDEIRA, ANA MARIA ANDRADE. } \\
\text { Interdisciplinaridade escolar no ensino médio: domínios epistêmicos como } \\
\text { possibilidade para elaboração e avaliação de um trabalho coletivo. Acta } \\
\text { Scientiarum. Education (Print), v. 38, p. 193-204, 2016. Disponível em: < } \\
\text { http://periodicos.uem.br/ojs/index.php/ActaSciEduc/article/view/23610>. } \\
\text { Acesso em: } 2 \text { abr. } 2017 \text {. }\end{array}$ & Artigo \\
\hline $\begin{array}{l}\text { Periódicos } \\
\text { Capes }\end{array}$ & $\begin{array}{l}\text { PETRUCCI-ROSA, Maria Inês. Políticas curriculares e identidades } \\
\text { docentesdisciplinares: a área de ciências da natureza e matemática no } \\
\text { currículo doEnsino Médio do estado de São Paulo (2008-2011), Ciência } \\
\& \text { Educação,Bauru, v. 20, n. 4, p. 937-953, 2014. Disponível em: < } \\
\text { http://www.infoteca.inf.br/endipe/smarty/templates/arquivos_template/upload_ } \\
\text { arquivos/acervo/docs/2939b.pdf >. Acesso em: } 2 \text { abr. } 2017 \text {. }\end{array}$ & Artigo \\
\hline $\begin{array}{l}\text { Periódicos } \\
\text { Capes }\end{array}$ & $\begin{array}{l}\text { Will, J. M., \& Pacheco, J. A. (2012). Currículo e Gestão Curricular: Uma } \\
\text { Reflexão Inicial. Espaço do Currículo, } 4 \text { (2), pp. 220-226.Disponível em: < } \\
\text { http://periodicos.ufpb.br/ojs2/index.php/rec/article/view/12338>. Acesso em: } 2 \\
\text { abr. 2017. }\end{array}$ & Artigo \\
\hline $\begin{array}{c}\text { Periódicos } \\
\text { Capes }\end{array}$ & 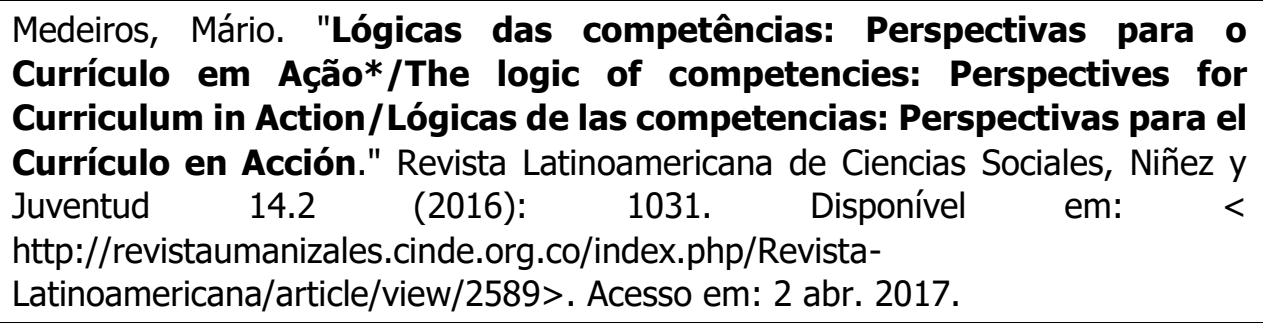 & Artigo \\
\hline $\begin{array}{l}\text { Periódicos } \\
\text { Capes }\end{array}$ & $\begin{array}{l}\text { Lay, Luís Antonio, et al. "Nível de Similaridade dos Currículos dos Cursos } \\
\text { de Ciências Contábeis de Instituições Catarinenses em Relação ao } \\
\text { Currículo Mundial Proposto pelo ISAR/UNCTAD/ONU." Revista } \\
\text { Evidenciação Contábil \& Finanças } 4.2 \text { (2016): 68-81. Disponível em: < } \\
\text { http://periodicos.ufpb.br/ojs/index.php/recfin/article/view/27940>. Acesso em: } \\
2 \text { abr. } 2017 .\end{array}$ & Artigo \\
\hline $\begin{array}{l}\text { Periódicos } \\
\text { Capes }\end{array}$ & $\begin{array}{l}\text { Vieira, Nuno Miguel. "Educação formal de Ciências: prioridade para o } \\
\text { cientista ou para o cidadão?" Revista Pedagógica 15.31 (2014): 183-194. } \\
\text { Disponível em: } \\
\text { http://bell.unochapeco.edu.br/revistas/index.php/pedagogica/article/view/364>. } \\
\text { Acesso em: } 2 \text { abr. } 2017 .\end{array}$ & Artigo \\
\hline $\begin{array}{l}\text { ATAS DOS } \\
\text { ENPEC }\end{array}$ & $\begin{array}{l}\text { Liotti, Luciane Cortiano, and Odisséa Boaventura de Oliveira. "O CURRÍCULO DE } \\
\text { CIÊNCIAS E AS ATUAIS REFORMAS: O QUE DIZEM AS PESQUISAS? In: Encontro } \\
\text { Nacional de Pesquisa em Educação em Ciências,7, Florianópolis: Anais do } \\
\text { Encontro Nacional de Pesquisa em Educação em Ciências, Florianópolis: } \\
\text { UFSC, } 2009 \text { Disponível } \\
\text { em:http://posgrad.fae.ufmg.br/posgrad/viienpec/pdfs/196.pdf. Acesso em: } 02 \\
\text { abr. 2017. }\end{array}$ & $\begin{array}{l}\text { Trabalho } \\
\text { em Anais }\end{array}$ \\
\hline $\begin{array}{l}\text { ATAS DOS } \\
\text { ENPEC }\end{array}$ & $\begin{array}{l}\text { OLIVEIRA, Gilvaneide Ferreira de; OLIVEIRA, Maria Lucia de; JÓFILI, Zélia Maria } \\
\text { Soares. Construção coletiva do currículo de ciências comoforma de envolver os } \\
\text { professores na sua implementação. In: Encontro Nacional de Pesquisa em } \\
\text { Educação em Ciências,7, Florianópolis: Anais do Encontro Nacional de } \\
\text { Pesquisa em Educação em Ciências, Florianópolis: UFSC, 2009. Disponível } \\
\text { em:http://posgrad.fae.ufmg.br/posgrad/viienpec/pdfs/196.pdf. Acesso em: } 02 \\
\text { abr. 2017. }\end{array}$ & $\begin{array}{l}\text { Trabalho } \\
\text { em Anais }\end{array}$ \\
\hline $\begin{array}{l}\text { ATAS DOS } \\
\text { ENPEC }\end{array}$ & $\begin{array}{l}\text { Santos, B. F. (2009). Currículo de ciências na escola primária norteamericana em } \\
\text { uma perspectiva funcional. In E. Mortimer (Org.). Atas do VII Encontro } \\
\text { Nacional de Pesquisa em Educação em Ciências (pp. 1-10). Florianópolis: } \\
\text { Associação Brasileira de Pesquisa em Educação em Ciências. ISSN: } 21766940 \\
\text { Disponível em: http://posgrad.fae.ufmg.br/posgrad/viienpec/pdfs/1178.pdf } \\
\text { Acesso em: } 02 \text { abr. } 2017 .\end{array}$ & $\begin{array}{l}\text { Trabalho } \\
\text { em Anais }\end{array}$ \\
\hline
\end{tabular}




\begin{tabular}{|c|c|c|}
\hline $\begin{array}{c}\text { ATAS DOS } \\
\text { ENPEC }\end{array}$ & $\begin{array}{l}\text { LOPES, N. C. et al. Uma análise crítica da proposta curricular do Estado de São } \\
\text { Paulo para o ensino de ciências: ideologia, cultura e poder. In: } \\
\text { ENCONTRONACIONAL DE PESQUISA EM EDUCAÇÃO EM CIÊNCIAS, 7., 2000, } \\
\text { Florianópolis.Anais... Florianópolis: ENPEC, 2000. Disponível } \\
\text { em:<http://posgrad.fae.ufmg.br/posgrad/viienpec/pdfs/312.pdf>. Acesso em: } \\
02 \text { abr. 2017. }\end{array}$ & $\begin{array}{l}\text { Trabalho } \\
\text { em Anais }\end{array}$ \\
\hline $\begin{array}{l}\text { ATAS DOS } \\
\text { ENPEC }\end{array}$ & $\begin{array}{l}\text { SANTOS, M.C.F. A noção de experiência em John Dewey, a educação progressiva } \\
\text { e o currículo de ciências. In: VIII ENCONTRO NACIONAL DE PESQUISA EM } \\
\text { EDUCAÇÃO EM CIÊNCIAS, 2011. Disponível em: } \\
\text { https://www.researchgate.net/profile/Maria_Ferreira_dos_Santos/publication/28 } \\
\text { 4338646_The_notion_of_experience_in_John_Dewey_progressive_education_an } \\
\text { d_science_curriculum/links/5651a40308aefe619b181f3b.pdf >. Acesso em: } 02 \\
\text { abr. 2017. }\end{array}$ & $\begin{array}{l}\text { Trabalho } \\
\text { em Anais }\end{array}$ \\
\hline $\begin{array}{l}\text { ATAS DOS } \\
\text { ENPEC }\end{array}$ & 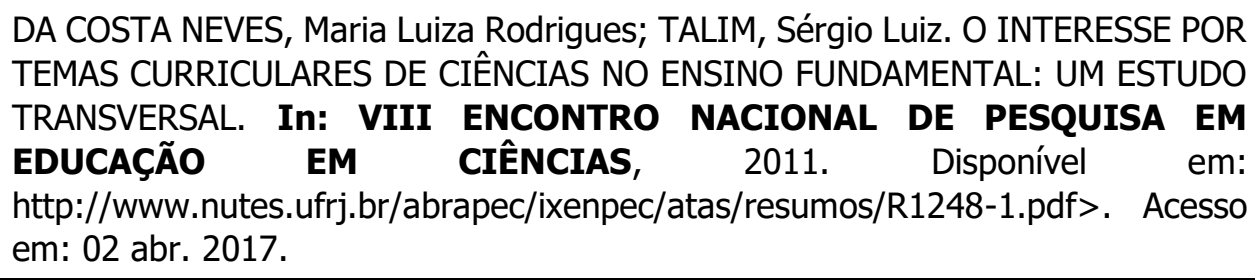 & $\begin{array}{l}\text { Trabalho } \\
\text { em Anais }\end{array}$ \\
\hline $\begin{array}{l}\text { ATAS DOS } \\
\text { ENPEC }\end{array}$ & $\begin{array}{l}\text { FERNANDES, João Paulo. O tema energia e a perspectiva Ciência-Tecnologia- } \\
\text { Sociedade (CTS) no Ensino de física: possíveis articulações nos documentos } \\
\text { oficiais curriculares. In: IX ENCONTRO NACIONAL DE PESQUISA EM } \\
\text { EDUCAÇÃO EM CIÊNCIAS, } 2013 . \quad \text { Disponível } \\
\text { http://www.nutes.ufrj.br/abrapec/ixenpec/atas/resumos/R0938-1.pdf>. Acesso } \\
\text { em: } 02 \text { abr. } 2017 .\end{array}$ & $\begin{array}{l}\text { Trabalho } \\
\text { em Anais }\end{array}$ \\
\hline $\begin{array}{l}\text { ATAS DOS } \\
\text { ENPEC }\end{array}$ & $\begin{array}{l}\text { GOUW, Ana Maria Santos et al. O interesse dos jovens brasileiros e o currículo de } \\
\text { Ciências: diálogos possíveis. In: X ENCONTRO NACIONAL DE PESQUISA EM } \\
\text { EDUCAÇÃO EM CIÊNCIAS, 2015. Disponível em: } \\
\text { https://www.researchgate.net/profile/Luiz_Tolentino- } \\
\text { Neto/publication/301202140_O_interesse_dos_jovens_brasileiros_e_o_curriculo } \\
\text { _de_Ciencias_dialogos_possiveis_The_interest_of_Brazilians_youngsters_and_th } \\
\text { e_science_curriculum_possible_dialogues/links/570c04c208aee0660351aa1e.pdf } \\
\text { >. Acesso em: } 02 \text { abr. 2017. }\end{array}$ & $\begin{array}{l}\text { Trabalho } \\
\text { em Anais }\end{array}$ \\
\hline $\begin{array}{l}\text { ATAS DOS } \\
\text { ENPEC }\end{array}$ & $\begin{array}{l}\text { Polanczky, C., Marmitt, D. B. N., Santos, R. A. Dos. A Não Neutralidade Da Ct No } \\
\text { Contexto Educacional Brasileiro: Configurações Curriculares E O Enfoque Cts In: } \\
\text { X ENCONTRO NACIONAL DE PESQUISA EM EDUCAÇÃO EM CIÊNCIAS, } \\
2015 \text { Disponível em: http://www.abrapecnet.org.br/enpec/x- } \\
\text { npec/anais2015/lista_area_09.htm>. Acesso em: } 02 \text { abr. } 2017 .\end{array}$ & $\begin{array}{l}\text { Trabalho } \\
\text { em Anais }\end{array}$ \\
\hline
\end{tabular}

Fonte: autores.

Após a leitura, traçamos como objetivos específicos compreender os fatores político-econômicos que interferiram no desenvolvimento da Educação Científica, analisar os fatores culturais e pedagógicos que permearam nessa história e discutir os caminhos que a Educação Científica tem para o século XXI. A iniciativa surge a partir de estudos realizados no âmbito das disciplinas Educação Brasileira, Educação Científica e Teorias da Educação que compõem o Programa de Pós-graduação em Educação Brasileira da Universidade Federal do Ceará.

As considerações aqui realizadas apresentam-se, também, como parte das contribuições do Grupo de Estudos e Pesquisa em Ensino de Ciências - GEPENCI, para a sociedade, buscando contribuir para a Educação Científica de Fortaleza, bem como no estado e no país. 


\section{HISTÓRIA DA EDUCAÇÃO CIENTÍFICA}

Segundo Oliveira e Freitas (2016), a pesquisa bibliográfica constitui-se de uma modalidade de investigação que parte de documentos científicos como fontes diretas de análise, além de ser uma das modalidades de investigação mais utilizadas em trabalhos de cunho histórico. Para compreender o desenvolvimento Educação Científica, dentro de nosso recorte histórico, organizamos nossos objetivos específicos em três tópicos: Influências Políticas e Econômicas no Ensino de Ciências do Século XX; Influências Culturais e Pedagógicas no Ensino de Ciências do Século XX; e a Educação Científica para o Século XXI.

No primeiro tópico abordaremos os aspectos políticos durante o pós-guerra, apontando a correlação de forças e a corrida armamentista como fatores determinantes no progresso da ciência, bem como a força da economia e dos agentes financiadores na educação, demarcando, assim, nosso primeiro objetivo, que é compreender os fatores político-econômicos que interferiram no desenvolvimento da Educação Científica.

A história nos mostra, conforme Ponce (2001), que a educação, como fenômeno social, deve ser entendida tão-somente quando analisada, também, socioeconomicamente, ou seja, cada modelo pedagógico articula-se com aspectos sociais, culturais, políticos, temporalmente e espacialmente, à comunidade vigente. Desta forma, buscamos analisar os fatores culturais e pedagógicos que permearam essa história, no segundo tópico.

Por fim, no último tópico apontaremos as novas perspectivas sobre a Educação Científica do novo século, buscando integrar as recentes pesquisas realizadas na área e às direções que se tem pensado e tomado a Educação Científica, finalizando, assim, com nosso último objetivo específico, que é discutir os caminhos que a Educação Científica tem para o século XXI.

\section{INFLUÊNCIAS POLÍTICAS E ECONÔMICAS NO ENSINO DE CIÊNCIAS DO SÉCULO XX}

Na primeira metade do século $\mathrm{XX}$, mesmo com um cenário devastador, as guerras alavancaram o desenvolvimento científico-tecnológico, "ao passo que foram reconhecidas como essenciais no desenvolvimento econômico, cultural e social de uma sociedade" (KRASILCHIK, 2000, p. 85). Esse progresso científico foi mais perceptível após a segunda guerra mundial, com início da guerra fria, quando os países passaram a investir em ciência e tecnologia na busca pela hegemonia industrial, científico e tecnológico (SANTOS, 2000).

Os dois blocos econômicos, capitalista, liderados pelos Estados Unidos da América (EUA), e socialista, capitaneada pela União das Repúblicas Socialistas Soviéticas (URSS), interferiam diretamente nos países que estavam em suas órbitas. No dia 6 de outubro de 1957, as mídias de grande massa anunciam o primeiro grande passo da corrida espacial, o lançamento do Sputnikii, que havia sido lançado dois dias antes pelo bloco socialista (CHASSOT, 2004).

Não satisfeitos com a derrota científica e tecnológica, catalisada pelos avanços soviéticos, os estadunidenses procuraram culpados pelo atraso na corrida armamentista, apontando seu sistema de ensino e mais precisamente o ensino de ciências como a falha a ser corrigida (SANTOS, 2000; LOPES; MACEDO, 2004). Sob pressão dos militares, os cientistas sentiram-se forçados a envolver-se com questões curriculares do ensino de ciências que, segundo Santos (2000), deu-se principalmente por dois motivos: 
Os cientistas, paulatinamente e contra sua vontade inicial, foram percebendo que tinham que se envolver com questões do currículo escolar especialmente por dois motivos: estimular as inclinações da juventude pela ciência e fortalecer a sua imagem junto à sociedade de modo a sustentar o imprescindível apoio público e financeiro do público leigo à pesquisa sem a ingerência dos militares (SANTOS, 2000, p. 6).

Nesse contexto, Santos (2000) apresenta que uma das principais intervenções no ensino básico foi a criação de projetos para a elaboração de materiais instrucionais para o ensino de ciências nas escolas secundárias. O autor ainda assinala a reforma do currículo escolar como "reforma do Sputnik", visto que "disparou uma onda de paranoia e medo entre os estadunidenses com relação à presumida superioridade tecnológica" (p. 7).

Tais projetos curriculares ${ }^{i v}$ eram direcionados para todas as ciências da natureza (Física, Química e Biologia) e recrutaram grandes cientistas que ganharam o recém-criado Prêmio Nobel, então financiado pela National Science Foundation(NSF), a qual surge desde a década de 50 para promover o progresso da ciência. Krasilchik (2000) considera este um marco no desenvolvimento do ensino de ciências.

Esse período marcante e crucial na história do ensino de Ciências, que influi até hoje nas tendências curriculares das várias disciplinas tanto no ensino médio como no fundamental, foi dando lugar, ao longo dessas últimas décadas, a outras modificações em função de fatores políticos, econômicos e sociais que resultaram, por sua vez, em transformações das políticas educacionais, cumulativas em função das quais ocorreram mudanças no ensino de Ciências (KRASILCHIK, 2000, p. 85).

Chassot (2004) compreende que o atraso estadunidense se acirra em 1961, quando Yuri Gagarin, o primeiro homem a ir ao espaço, tripulando a Vostok I, pronuncia a clássica frase "A terra é azul!". Ainda assim, a força do bloco capitalista era perceptível. A influência nos demais países da américa se tornava uma questão de tempo. Apoiando o golpe militar de 1964 no Brasil, os Estados Unidos da América (EUA) garantem acordos econômicos de estreitamento com o gigante da américa do sul (ROMANELLI, 2014). A essa altura, a compra dos projetos estrangeiros que salvariam o ensino de ciências e, consequentemente, o progresso científico, tornaram-se também objetivos do ensino de ciências no Brasil (CHASSOT, 2004).

Influenciados economicamente pelos EUA, os governos militares brasileiros buscam seguir a lógica capitalista, com a reabertura ao capital estrangeiro e a venda de estatais, havendo um maior investimento na economia e na industrialização do país. Com isso a demanda social aumentava à medida que a base social crescia e a econômica também.

Pode-se perceber que o sistema educacional foi marcado por dois momentos nitidamente definidos em sua evolução a partir de 1964. O primeiro corresponde àquele em que se implantou o regime e se traçou a política da recuperação econômica. Ao lado da contenção e da repressão, que bem caracterizaram a fase, constatou-se uma aceleração do ritmo do crescimento da demanda social de educação, o que provocou, consequentemente, um agravamento do sistema educacional, crise que já vinha de longe (ROMANELLI, 2014, p. 202).

Segundo Romanelli (2014), essa foi a justificativa que acabou sendo dada pelo governo, para a assinatura de uma série de convênios entre o Ministério da Educação e Cultura (MEC) e a Agency for International Development (AID), para a contratação de assistência técnica e cooperação financeira, o objetivo dessa agência era promover a organização do sistema educacional brasileiro, este é então o período dos chamados "Acordos MEC-USAID". 
Os acordos entre o Ministério da Educação (MEC) e USAID direcionavam a educação para a reforma que estimulava maior objetividade e praticidade - características propostas pelas agências financiadoras, bancos internacionais e o setor econômico (LOMBARDI; SAVIANI; NASCIMENTO, 2006; SHIROMA et al., 2007).

A maior parte desses projetos foi implantada na recém-criada rede de Centros de Treinamentos de Ensino de Ciências, bem como ligada aos centros de ciências das universidades, segundo Lorenz e Barra (1986), desde a metade do século, quando sucessivos governos buscaram renovar a Educação Científica em todos os níveis de educação formal do país, criando-se, em 1965, seis centros de ciências em diversas regiões do país para fortalecer a Educação Científica nos âmbitos primário e secundário.

O Centro de Ciências do Nordeste (CECINE), o primeiro a ser implantado e os outros, fundados subsequentemente - CECIRS em Porto Alegre, o CECIMIG, em Belo Horizonte, o CECIGUA, no Rio de Janeiro, o CECISP, em São Paulo e o CECIBA, em Salvador. Esses centros, "tinham como objetivo treinar professores e produzir e distribuir livros-texto e materiais para laboratório para as escolas de seus respectivos estados. Ao IBECC coube a importante tarefa de treinar líderes e administradores para atuar nos centros recém-criados (LORENZ; BARRA, 1986, p. 1975).

Muitas críticas (SORIANO et al, 1974; GIL-PEREZ, 1993; PEREIRA; SILVA, 2009; LOGUERCIO; DEL PINO, 2007) à tais projetos convergem, apontando que essas experiências davam grande ênfase à atividade autônoma dos estudantes e ao uso da experimentação (PEREIRA; SILVA, 2009), contudo o indutivismo e o behaviorismo impediam o desenvolvimento da criatividade, pois tais experiências descontextualizadas pareciam mais receitas prontas do que atividades que proporcionassem a construção crítica do conhecimento científico. (GIL-PEREZ, 1993; LOGUERCIO; DEL PINO, 2007). Alguns autores são mais específicos e colocam ainda algumas considerações em suas pesquisas sobre os projetos que foram traduzidos para a versão brasileira:

São algumas das dificuldades na utilização desses projetos: i) Desnível entre o projeto e o ensino "clássico" de química; ii) a ausência de livro-texto em língua portuguesa; iii) dificuldade de encontrar certos equipamentos; iv) a não-existência local de determinados reagentes; v) como o CBA dá grande ênfase à eletroestática, o alto teor higrométrico do Nordeste torna as experiências difíceis de serem observadas (SORIANO et al.,1974, p. 7).

Ainda durante a década de 1970, o governo brasileiro solicitou novos recursos para o desenvolvimento científico do país, porém o parecer do próprio Banco Mundial foi que a verba havia sido desperdiçada, deixando apenas uma dívida a pagar. A crítica ao dinheiro gasto refere-se às feiras de ciências e projetos que tornavam o ensino de ciências cada vez mais demonstrativo (CHASSOT, 2004).

O ensino de ciências com demonstrações seria o caminho apontado para ensinar ciências de forma objetiva, prática e rápida. O crescimento populacional e urbano exigia, do mercado de trabalho, profissionais aptos em curtos períodos.

Em 1979, Theodore Schultzo ganha o prêmio Nobel de Economia (1979) apresentando sua pesquisa sobre o trabalho humano, ao afirmar que o trabalho qualificado é uma forma direta de aumento da produtividade e, consequentemente, do lucro. Dentro dessa lógica, a educação intensificou a função de qualificar a população para o mercado de trabalho de forma mais aligeirada (MARTINS, 2016).

No campo educacional, desdobrou-se na predominância da visão tecnicista, com a ideia de que a educação é o pressuposto do desenvolvimento econômico e individual, pois, ao educar-se, o indivíduo estaria valorizando a si próprio, na mesma lógica que valoriza o capital (MARTINS, 2016, p. 55). 
A Reforma Tecnicista apresenta-se como proposta de treinamento e aperfeiçoamentos de profissionais, adequando-se às demandas do mercado. Dentro desse processo todas as metas estabelecidas têm como único objetivo o desenvolvimento econômico do país (MENDES-SOBRINHO, 2007). Assim, o desenvolvimento do ensino de ciências tornou-se prioridade para que fosse possível treinar cientificamente a população para que esta fosse capaz de trabalhar e produzir o progresso do país.

É também na transição entre os decênios 70 e 80 que chega a proposta do telensino no Brasil, como estratégia de acesso à educação ao maior número de pessoas possível e em pouco tempo. Vieira e Farias (2002) explicam que o telensino do Ceará seguiu modelos já implantados em outros estados:

No Ceará, ocorreu em 1974. Estávamos seguindo o modelo que já estava sendo implantado em outros estados do país, como São Paulo, que implantou a TV Educativa em 1967; Pernambuco, em 1968; Maranhão, 1969 e Amazonas, que passou a utilizála a partir de 1971 (VIEIRA; FARIAS, 2002, p. 2).

Segundo Brandão e Dias (2003), esse modelo replicado nos estados brasileiros refletiu o momento de efervescência das ideias tecnicistas, as quais têm por base os princípios da racionalidade técnica com forte influência dos modos de produção capitalistas.

Em 1990, a Conferência Mundial sobre Educação, na Tailândia, apresenta a declaração mundial sobre a educação para todos, onde se explicita que há a necessidade de estabelecer um novo modelo educacional que deveria moldar a educação dos países periféricos.

Em consequência, nós, os participantes da Conferência Mundial sobre Educação para Todos, reunidos em Jomtien, Tailândia, de 5 a 9 de março de 1990: relembrando que a educação é um direito fundamental de todos; [...]; reconhecendo que o conhecimento tradicional e o patrimônio cultural têm utilidade e valor próprios, assim como a capacidade de definir e promover o desenvolvimento; [...]; reconhecendo que uma Educação Básica adequada é fundamental [...]; e reconhecendo a necessidade de proporcionar às gerações presentes e futuras uma visão abrangente de Educação Básica [...], para enfrentar a amplitude e a complexidade do desafio, proclamamos a seguinte Declaração Mundial sobre Educação para Todos: satisfação das necessidades básicas de aprendizagem (TAILANDIA, 1990).

Tal reforma educacional deveria reorganizar os processos educativos para a efetivação dos objetivos de sustentabilidade, equidade e de combate à pobreza, cujo foco seria na Educação Básica. Contudo, as transformações do ensino de ciências não se devem somente aos pressupostos políticos e econômicos, mas a fatores culturais e pedagógicos que foram sendo alterados paralelamente. Para isso, resgataremos um pouco da história das teorias educacionais no tópico seguinte.

\section{INFLUÊNCIAS CULTURAIS E PEDAGÓGICAS NO ENSINO DE CIÊNCIAS DO SÉCULO XX}

Compreendendo que, principalmente durante a segunda metade do século $X X$, o bloco capitalista, sob a influência dos Estados Unidos da América, influenciou muitas das políticas e financiamentos para a educação brasileira (SHIROMA et al., 2007) e consequentemente para ensino de ciências (KRASILCHIK, 2000), resgataremos a concepção pedagógica de John Dewey, um dos maiores pensadores educacionais estadunidense dessa época.

Lourenço Filho, no prefácio da obra "Vida e Educação" de Dewey (1978), destaca os dois pressupostos basilares da obra: o primeiro propõe que não há separação entre vida e educação e o segundo, que 
a finalidade da educação é mais educação. Se não há separação entre vida e educação, a todo momento estamos aprendendo com nossas experiências e vivências. Nessa perspectiva, a arte e a estética inserem-se como componentes pedagógicos essenciais nas vivências e experiência formativa de sujeitos criativos e críticos.

Dewey é considerado utilitarista por transformar as utilidades individuais em patrimônio social (FERREIRA; GUTMAN, 2005), instrumentalista pela sua metáfora entre a ciência e progresso, e funcionalista ao considerar que a ciência desenvolve a função de relacionar a experiência conflitante e a experiência integrada (RODRIGUES; BORGES, 2008), ou seja, a experiência conflitante tem a função de iluminar as possibilidades e os novos caminhos, transformando-se, assim, em uma experiência integrada.

O teórico compreendia que a educação e, consequentemente, o processo educativo, é uma reconstrução dessas experiências, tendo o educando a liberdade de definir seus próprios percursos formativos. Criticou o ensino de ciências de seu tempo, uma vez que compreendia a ciência como um método de pensamento e uma atitude mental que é capaz de transformar formas de pensamento, desde que deixasse de limitar-se ao simples acúmulo de conhecimento.

A experiência, desta forma, segundo o Dewey, é uma fase da natureza, onde a situação e o agente relacionam e modificam-se. Ou seja, a educação, o processo educativo e, consequentemente, a experiência dão-se por meio de relações. A experiência significa, para Dewey (1978), 'agir sobre outro corpo e sofrer de outro corpo uma reação'.

Essa utilização que Dewey atribui à experiência é peculiar e pouco compreendida, o que acabou sendo utilizada para fundamentar a inserção de atividades práticas no ensino de ciências, ficando conhecido como pedagogia de projetos (RODRIGUES; BORGES, 2008). Tal perspectiva encontra-se, segundo Morais (1998), dentro da concepção empirista e indutivista, consistindo em derivar, após a observação do fenômeno, generalizações, indo do particular para o geral.

Rosito (2000) considera que esse tipo de concepção epistemológica tende a desvalorizar a criatividade do trabalho científico, conduzindo o aluno a aceitar o conhecimento como verdades inquestionáveis, além de aumentar a rigidez e intolerância a pluralidade de opiniões.

Tendo como a matriz educacional o funcionalismo de Dewey, os kits com experiências científicas propostos pelos projetos comprados na ditadura buscavam reproduzir a lógica semelhante à atividade científica. Fundamentadas no ensino por descoberta, tais atividades deveriam ser desenvolvidas segundo uma racionalidade derivada da atividade científica e tinham a finalidade de contribuir com a formação de futuros cientistas (NASCIMENTO; FERNANDES; MENDONÇA, 2010).

A concepção de que a ciência é empírica e indutivista foi por muitos anos, e tem sido até hoje, a mais presente concepção sobre a natureza da ciência para os professores de ciências e leigos (SILVA et al., 2016). Suas fundamentações basilares estão na Antiguidade Clássica, quando Aristóteles (384332 a.C.) propusera o chamado método indutivo, ou raciocínio indutivo, para a produção do conhecimento. Com a sistematização indutiva, a hegemonia desse modelo de ciência baseado na experimentação se estabelece, sustentada pela defesa das observações seguras e da objetividade e neutralidade dos cientistas (SILVEIRA; OSTERMANN, 2002).

As críticas ao modelo de ciência empírica-indutiva, fortemente presente nos projetos da década de 70, devem-se a alguns fatores acumulados por muitos autores (SILVEIRA; OSTERMANN, 2002; 
CHASSOT, 2004). No artigo "A insustentabilidade da proposta indutivista de descobrir a lei a partir de resultado experimentais", Silveira e Ostermann (2002) resgatam as críticas contemporâneas à concepção empírica-indutivista, representadas por diversos autores (POPPER, 1975; LAUDAN, 1977; KUHN, 1978; CHALMERS, 1987; FEYERABEND, 1993 apudSILVEIRA; OSTERMANN, 2002). A maioria dos autores citados por Silveira e Ostermann (2002) é consonante em suas críticas ao modelo indutivista apontando, por exemplo, a dificuldade de considerar experiências individuais capazes de generalizações científicas.

Segundo Chassot (2004), a ciência que busca as teorias a partir dos experimentos e observações neutras acaba por não considerar os pressupostos teóricos e a parcialidade dos cientistas. Uma das críticas específicas aos projetos estadunidenses comprados pelos governos da ditadura deve-se ao afastamento da realidade do aluno, o qual, por sua vez, deve se buscar o saber científico.

Laudan (1977), um dos críticos ao modelo empírico-indutivista, considera que a ciência é, em essência, uma das atividades de resolução de problemas, e que para avaliarmos os méritos das teorias científicas devemos procurar sua relevância para a realidade, e não se constituem de "verdades", ou se foram "bem confirmadas". Cachapuz et al. (2005) reforçam:

De forma geral, os empiristas e os indutivistas, para quem todo o conhecimento vem da experiência, tentam reduzir a experimentação a uma manipulação de variáveis. 0 investigador faz, antes de tudo, um inventário empírico de parâmetros susceptíveis de ter influência no fenômeno estudado para, em seguida, os fazer variar e, eventualmente, depois dos resultados obtidos, estabelecer uma lei que lhes dê sentido e coerência (CACHAPUZ et al., 2005, p. 95).

Mesmo com tal acúmulo crítico a esse modelo de ciência, ainda hoje temos marcas graves no ensino de ciências, pois muitos professores/educadores ainda mantêm uma concepção de ciências empírica e indutivista, ou seja, uma concepção de ciência fragmentada e individual, e acabam por trabalhar a educação cientifica pautados nesta concepção de ciência, assim como orientações e projetos curriculares também.

Mas a busca de uma ciência não neutra nem fragmentada e de uma Educação Científica que se proponha, também metodologicamente, contribuir com a realidade da sociedade atual tem sido feita. No próximo tópico, discutiremos quais as novas perspectivas para a Educação Científica no século XXI.

\section{A EDUCAÇÃO CIENTÍFICA PARA O SÉCULO XXI}

O resgate histórico nos mostra que a preocupação com a qualidade do ensino de ciências foi marcante na metade do século XX, durante a corrida armamentista, na guerra fria, onde a competição entre blocos econômicos, capitalistas e socialistas, forçou-os a investir em tecnologia e na educação de novos cientistas. Apesar da problemática do ensino indutivista proposto pelos kits de ciências, onde o aluno aprendia a fazer generalizações a partir de experiências isoladas e descontextualizadas, 0 ensino de ciências teve um grande investimento, inclusive na criação de uma rede de centros de ciências para pensar a formação. $O$ acesso à Educação Científica foi possibilitado com a utilização do tele-ensino, que se encaixa ainda na lógica de formação aligeirada de mão-de-obra qualificada, necessidade evidenciada pela demanda social. O tele-ensino apresentou algumas problemáticas como o atraso dos manuais de apoio, má formação e remuneração dos orientadores de aprendizagens. 
Com a virada do século, os investimentos em ciência e tecnologia tornaram-se cada vez mais evidentes, a tecnologia e a ciência avançaram muito com a produção de nanotecnologias, biorremediadores, geolocalizadores e com a globalização da informação trazida pela instantaneidade da internet. Nesse novo contexto, segundo Pozo e Crespo (2009), vivemos agora na sociedade da informação, onde o conhecimento acumulado encontra disponível na internet, tendo, agora, a escola e, consequentemente, a Educação Científica, um novo objetivo.

Se o acesso à informação foi um grande avanço, essas informações nem sempre são verídicas. Essas informações nem sempre são seguras, pois "um filme pode mostrar uma informação superficial, fragmentada e às vezes, deformada" (POZO; CRESPO, 2009, p. 94). Nessa nova situação o conhecimento difere-se da informação por estar organizado e sistematizado, tendo a escola esse novo olhar sobre dar as ferramentas aos estudantes para que possam filtrar tais informações de modo a facilitar suas tomadas de decisões diárias.

Desta forma, surgem na Educação Científica as ideias de alfabetização científica e de letramento científico. Para Ferreira (2013, p. 23):

A categoria 'letramento em ciências' refere-se à forma como as pessoas farão uso dos conhecimentos científicos, seja em sua vida profissional, social ou pessoal, promovendo uma melhoria na qualidade de vida ou auxiliando na tomada de decisões frente a um mundo em constantes mudanças. Portanto, a alfabetização científica no ensino de Ciências Naturais no Ensino Fundamental é compreendida como um processo pelo qual a linguagem das ciências adquire significados, constituindo-se num meio para o indivíduo ampliar o seu universo de conhecimento, a sua cultura, como cidadão inserido na sociedade.

Desta forma, a alfabetização científica é o processo, dentro da Educação Científica, no qual ocorre compreensão da linguagem e dos códigos específicos da área, constituindo os processos de leitura e escrita dos conhecimentos e habilidades em nível individual, enquanto o letramento científico é a utilização dos conhecimentos adquiridos na argumentação durante a tomada de decisões futuras, sendo necessário a articulação entre linguagem e códigos em um plano social, conforme Mammed e Zimmermman (2005). ${ }^{v}$

Para isso, alguns trabalhos apontam a abordagem Ciência-Tecnologia-Sociedade (CTS), ou ainda Ciência-Tecnologia-Sociedade-Ambiente (CTAS), como um dos melhores caminhos para o letramento científico (FERNANDES, 2013; VIEIRA, 2014; BONFIM; GUIMARÃES, 2015; DOURADO, 2015; POLANCZKY; SANTOS, 2015; TERNEIRO-VIEIRA; MARQUES-VIEIRA, 2016)

Segundo Polanczky e Santos (2015), o movimento CTS surge no Século XX, em resposta aos constantes problemas sociais, ambientais e econômicos causados pelo progresso. Dourado (2015) problematiza a relação ciência-tecnologia-sociedade, colocando o ambiente como balizador dessa discussão, propondo e reforçando a abordagem CTSA na Educação Científica.

Bonfim e Guimarães (2015) apontam que o movimento buscou trazer o olhar crítico para os desastres ambientais, como desmatamentos e desertificações, como para as problemáticas causadas pela industrialização, como a poluição e o aquecimento global. Destacam ainda que as críticas diante dos problemas políticos, econômicos e sociais são reflexos da crescente contraposição aos pressupostos cientificistas e buscam reforçar que a ciência e tecnologia devem ser estudadas e abordadas como processos sociais. 
Essa abordagem pode ser operacionalizada mediante implicação em situações de aprendizagens incitativas, onde deve-se estimular o desenvolvimento da capacidade de pensar e de mobilizar os conceitos, respeitando normas e valores sociais, conforme proposto por Terneiro-Vieira e MarquesVieira (2016).

Fernandes (2013) e Vieira (2014) contribuem questionando a inserção da abordagem CTSA nos currículos. Fernandes (2013) ressalta que a inserção no currículo de ciências modificaria novas implicações éticas, ambientais, sociais e econômicas, pontos importantes na formação para a cidadania. Vieira (2014) aponta que a abordagem CTSA contribui na formação do cientista e do cidadão, sendo necessária a inclusão dessa abordagem para a formação de uma sociedade cientificamente letrada.

Para construir uma sociedade cientificamente letrada devemos pensar, além da abordagem, o que se espera de um processo de Educação Científica, compreendido pela alfabetização e letramento científico. Desta forma, é necessário delimitarmos quais as metas e objetivos que se tem esperado de um processo educacional em ciências naturais.

Buscamos, na literatura específica do ensino de ciências, objetivos e metas esperadas para um processo de Educação Científica. Resgatamos aqui três fontes encontradas Jiménez e Sanmartí (1997), Pozo e Crespo (2009), Vieira (2014).

Segundo Jiménez e Sanmartí (1997 apudPOZO e CRESPO, 2009) podem ser consideradas metas para a Educação Científica: a aprendizagem dos conceitos e modelos; o desenvolvimento de habilidades cognitivas e raciocínio; o desenvolvimento de habilidades experimentais; o desenvolvimento de atitudes e valores e a construção do processo científico. Para Pozo e Crespo (2009) é necessário que as metas, os conteúdos e os métodos de ensino considerem, além dos aspectos conceituais, as características dos alunos a quem esse ensino vai ser direcionado e as demandas sociais educacionais. Os autores discutem a necessidade da inclusão de conteúdos procedimentais e atitudinais, além dos conceituais, já presentes.

Ou seja, é preciso trazer para as aulas de ciências aspectos procedimentais, que consistem na utilização dos conhecimentos conceituais no cotidiano dos educandos, e aspectos atitudinais, que permitam uma reflexão crítica sobre os valores dos conhecimentos (POZO; CRESPO, 2009).

Vieira (2014) ressalta ainda as metas propostas para o letramento científico pelo Relatório do Programa Internacional de Avaliação de Estudantes (Relatórios PISA) referem-se:

Ao conhecimento científico, e à utilização desse conhecimento para identificar questões, adquirir novos conhecimentos, explicar fenômenos científicos e elaborar conclusões fundamentadas sobre questões relacionas com ciência; à compreensão das características próprias da ciência enquanto forma de conhecimento e de investigação; à consciência do modo como ciência e tecnologia influenciam os ambientes material, intelectual e cultural das sociedades; à vontade de envolvimento em questões relacionadas com a ciência e com o conhecimento científico, enquanto cidadão consciente (VIEIRA, 2014, p. 187).

Há, nos três grupos de metas propostas para a Educação Científica, a preocupação com um ensino que não se restrinja aos fatos, conceitos e fenômenos, mas que busque agregar as habilidades, as técnicas e os métodos de como se investiga nas áreas científicas, como também o respeito às normas e valores da sociedade, da ciência e das pessoas, ou seja, que sejam abordados conteúdos conceituais, atitudinais e procedimentais (POZO; CRESPO, 2009). 
Busca-se, assim, confrontar o que se espera do processo de Educação Científica com as expectativas de aprendizagens de ciências propostas pelos sistemas de ensino e, assim, fortalecer o processo de ensino e aprendizagem nos espaços escolares.

\section{CONSIDERAÇÕES FINAIS}

Esta revisão de literatura buscou compreender a história da Educação Científica do final do século XX até o começo do século XXI a partir de três objetivos específicos. O primeiro compreender os fatores político-econômicos que interferiram no desenvolvimento da Educação Científica, e nos trouxe a compreensão que o ensino de ciências surgiu a partir dos interesses político-econômicos e que a disciplina de ciências ganhou visibilidade devido as disputas capitalistas entre nações, partindo da compreensão de que ciência é progresso.

Em nosso segundo objetivo específico, analisamos os fatores culturais e pedagógicos que permearam nessa história, onde podemos perceber que as aulas de ciências ainda têm sido marcadas fortemente pelas concepções positivistas, funcionalistas e indutivistas, características da educação estadunidense, apesar dessa concepção de ciência ainda limitar o processo de construção do conhecimento científico.

Por fim, discutimos, em o último objetivo específico, os caminhos que a Educação Científica tem para o século XXI, partindo do olhar histórico e filosófico sobre a Educação Científica para o século XXI, pois, agora, a Educação Científica busca, conforme as últimas pesquisas da área, ser entendida como formação de sujeitos capazes de articular conceitos, procedimentos e atitudes socialmente construídas no processo de alfabetização científica, com situações reais e cotidianas em um plano social, tendo este indivíduo e essa sociedade argumentos suficientes para selecionar as informações disponíveis na sociedade da informação e organizá-las para suas tomadas de decisões, as quais são capazes de transformar socialmente o futuro da humanidade.

Assim, esperamos que, ao final dessa revisão de literatura, partindo da revisão dos aspectos que influenciaram o desenvolvimento da educação até a construção das novas perspectivas para o século XXI, possamos ter contribuído com a área de pesquisa em Educação Científica, bem como ter despertado novos caminhos e possibilidades de investigação na área.

\section{REFERÊNCIAS}

BONFIM, H. C. C.; GUIMARÃES, O. M. Abordagem CTS no ensino de ciências nos anos iniciais do ensino fundamental: um caminho para a cidadania. In: CONGRESSO NACIONAL DE EDUCAÇÃO EDUCERE, 12., 2015, Curitiba. Anais... Curitiba: PUC-PR, 2015. p. 16437-16452.

BRANDÃO, M. de L. P.; DIAS, A. I. Imagens distorcidas: atualizando o discurso sobre o telensino no Ceará. Fortaleza: Imprensa Universitária, 2003.

CACHAPUZ, A. et al. (Org.). A necessária renovação do ensino das ciências. São Paulo: Cortez, 2005.

CHALMERS, A F. Qué es esa cosa llamada ciencia? Madrid: Siglo Veitiuno, 1987. 
CHASSOT, A. Ensino de ciências no começo da segunda metade do século da tecnologia. In: LOPES, Alice Casimiro; MACEDO, Elizabeth (Org.). Curriculo de ciencias em debate. Campinas: Papirus, 2004. Cap. 1, p. 13-44.

DEWEY, J. Vida e educação. 5. ed. São Paulo: Nacional, 1978.

DOURADO, S. M. de A. Ensino de ciências no $5^{\circ}$ ano do ensino fundamental: o currículo modelado e aspectos do currículo em ação. 2015. 133 f. Dissertação (Mestrado) - Programa de Pósgraduação em Educação Escolar, Faculdade de Ciências e Letras, Universidade Estadual Paulista, Araraquara, 2015. Disponível em: <https://repositorio.unesp.br/bitstream/ handle/11449/124144/000828984.pdf?sequence=1\&isAllowed=y>. Acesso em: 2 abr. 2020.

FERREIRA, A. A. L.; GUTMAN, G. O funcionalismo em seus primórdios: a psicologia a serviço da adaptação. In: JACÓ-VILELA, A. M.; FERREIRA, A. L. L.; PORTUGAL, F. T. (Org.) História da psicologia: rumos e percursos. Rio de janeiro: NAU, 2005. p. 121-140.

FERREIRA, Regina Maria Santiago. Letramento científico: conhecimentos construídos ao longo do ensino fundamental. 2013. 72 f. Dissertação (Mestrado) - Faculdade de Educação, Pontifícia Universidade Católica do Rio Grande do Sul, Porto Alegre, 2013. Disponível em: <http://repositorio.pucrs.br/dspace/bitstream/10923/5558/1/000446983-Texto+Completo-0.pdf>. Acesso em: 2 abr. 2017.

FEYRABEND, P. Contra o método. Lisboa: Relógio D'Água, 1993.

GIL-PEREZ, D. Contribución de la historia y de la filosofia de las ciências al desarrollo de um modelo de enseñanza/apredendizaje como investigación. Enseñaza de las ciências, [s. l.], v. 11, n. 2, p. 197212, 1993.

JIMÉNEZ, A. P.; SANMARTÍ, N. ¿Qué ciencia enseñar?: objetivos y contenidos de la educación secundaria. In: CARMEN, del L. La enseñanza y el aprendizaje de las ciencias de la naturaleza en la educación secundaria. Barcelona: ICE-Horsori, 1997. p. 17-46.

KRASILCHIK, M. Reformas e realidade: o caso do ensino das ciências. São Paulo Perspec., São Paulo, v. 14, n. 1, p. 85-93, mar. 2000. Disponível em: <http://www.scielo.br/scielo.php?script=sci_arttext\&pid=S0102$88392000000100010 \&$ Ing $=e n \& n r m=$ iso $>$. Acesso em: 8 jan. 2020.

KUHN, T. A estrutura das revoluções científicas. São Paulo: Perspectiva, 1978.

LAUDAN, L. La metodologia de los programas de investigación científica. Madrid: Alianza, 1989.

LEITE, R. C. M. A construção coletiva do conhecimento científico: um exemplo no ensino de genética. 2004. 211 f. Tese (Doutorado) - Curso de Educação, Universidade Federal de Santa Catarina, Florianópolis, $2004 . \quad$ Disponível em: <https://repositorio.ufsc.br/bitstream/handle/123456789/87537/204947.pdf?sequence=1\&isAllowed =y>. Acesso em: 22 maio 2020.

LOGUERCIO, R. Q.; DEL PINO, J.C. . Em Defesa do Filosofar e do Historicizar Conceitos Científicos. Revista História da Educação (UFPel), v. 23, p. 67-96, 2007. LOMBARDI, J. C.; SAVIANI, D.; NASCIMENTO, M. I. M. (Org.). Navegando pela história da educação brasileira. Campinas: Graf Fe Histedbe, 2006. 1. CD-ROM. 
LOPES, A. C. Políticas de currículo: mediação por grupos disciplinares de ensino de ciências e matemática. In: LOPES, A. C.; MACEDO, E. F. de (Org.). Currículo de ciências em debate. Campinas: Papirus, 2004. p. 45-76.

LORENZ, K. M.; BARRA, V. M. Produção de materiais didáticos de ciências no Brasil, período: 1950 a 1980. Ciência e Cultura, São Paulo, v. 38, n. 12, p. 1970-1983, dez. 1986.

MAMEDE, M.; ZIMMERMANN, E. Letramento científico e CTS na formação de professores para o ensino de física. In: SIMPósIo NACIONAL DE ENSINO DE FÍSICA, 16., 2005, Rio de Janeiro. Anais... Rio de Janeiro, 2005.2 Disponível <http://www.sbf1.sbfisica.org.br/eventos/snef/xvi/cd/resumos/T0264-1.pdf>. Acesso em: 6 nov. 2019.

MARTINS, M. A. R. Pacto Nacional pela Alfabetização na Idade Certa (PNAIC): a educação como legitimação e dominação social. 2016. 199 f. Dissertação (Mestrado em Educação) Faculdade de Educação, Universidade Federal do Ceará, Fortaleza, 2016. Disponível em: <http://www.repositorio.ufc.br/bitstream/riufc/16426/1/2016_dis_marmartins.pdf>. Acesso em: 8 jan. 2020

MEDEIROS, M. Lógicas das competências: perspectivas para o currículo em ação. Revista Latinoamericana de Ciencias Sociales, Niñez y Juventud, Manizales, Colombia, v. 14, n. 2, p. 1031, 2016. Disponível em: <http://revistaumanizales.cinde.org.co/index.php/RevistaLatinoamericana/article/view/2589>. Acesso em: 2 abr. 2017.

MENDES SOBRINHO, J. A. de C. 0 ensino de ciências naturais na Escola Normal: aspectos históricos. Teresina: Edufpi, 2002.

MORAES, R. O significado da experimentação numa abordagem construtivista: o caso do ensino de Ciências. In: BORGES, R. M. R.; MORAES, R. Educação em ciências nas séries iniciais. Porto Alegre: Sagra-Luzatto, 1998. p. 29-45.

NASCIMENTO, F.; FERNANDES, H. L.; MENDONÇA, V. M. O ensino de ciências no Brasil: história, formação de professores e desafios atuais. Revista História, Sociedade e Educação no Brasil, Campinas, v. 39, p. 225-249, 2010.

OLIVEIRA, M. M. D. de; FREITAS, I. Currículos de história e expectativas de aprendizagem para os anos finais do ensino fundamental no Brasil (2007/2012). História Hoje, São Paulo, v. 1, n. 1, out. 2012. Disponível em: <file://C:/Users/Lucas\%20Ribeiro/Desktop/ mestrado\%20educa\%C3\%A7\%C3\%A3o/11-26-1-SM.pdf>. Acesso em: 28 abr. 2016.

ORGANIZAÇÃO DAS NAÇÕES UNIDAS PARA A EDUCAÇÃO, A CIÊNCIA E A CULTURA. Declaração Mundial sobre Educação para Todos. Jomtien, Tailândia, 1990.

PEREIRA, C. L. N.; SILVA, R.R. A história da ciência e o ensino de ciências. Revista Virtual de Gestão de Iniciativas Sociais, edição especial, mar. 2009. Disponível em: <http://www.Itds.ufrj.br/gis/a_historia.htm>. Acesso em: 8 jan. 2017

POLANCZKY, C.; SANTOS, R. A. dos. A não neutralidade da CT no contexto educacional brasileiro: configurações curriculares e o enfoque CTS. In: ENCONTRO NACIONAL DE PESQUISA EM EDUCAÇÃO EM CIÊNCIAS, 10., 2015, Águas de Lindoia. Anais... Águas de Lindoia, 2015. Disponível em: http://www.abrapecnet.org.br/enpec/x-enpec/anais2015/lista_area_09.htm>. Acesso em: 2 abr. 2017.

PONCE, A. Educação e luta de classes. 18. ed. São Paulo: Cortez, 2001. 
POPPER, K R. Conhecimento objetivo. São Paulo: EDUSP, 1975.

POZO, J. I.; CRESPO, M.A.G. A aprendizagem e o ensino de ciências. Porto Alegre: Artmed, 2009.

RODRIGUES, B. A.; BORGES, A. T. O ensino de ciências por investigação: reconstrução histórica. In: ENCONTRO DE PESQUISA EM ENSINO DE FÍSICA, 11., 2008, Curitiba. Anais... Curitiba: SBF, 2008.

ROMANELLI, O. de O. História da educação no Brasil. 22. ed. Petrópolis: Editora Vozes, 2014.

ROSITO, B. A. O ensino de ciências e a experimentação. In: MORAIS, Roque (Org.). Construtivismo e o ensino de ciências. Porto Alegre: Edpucrs, 2000. p. 195-209. Disponível em: $<$ https://books.google.com.br/books?id=IWIsPQqz6MgC\&pg=PA195\&lpg=PA195\&dq= berenicealvaresrosito\&source $=$ bl\&ots $=f 82 a R q s s v A \& s i g=g s V \_X 3 J Q V E N 0 t F g 7 K k P s P I a J J G 0 \& h l=p t-$ $\mathrm{BR} \& \mathrm{sa}=\mathrm{X} \& \mathrm{ved}=0$ ahUKEwiB1PjB5ubPAhXGDJAKHf3JCAEQ6AEIJTAC\#v =onepage\&q=berenice alvares rosito\&f=false $>$. Acesso em: 30 jan. 2017.

SANTOS, B. F. Currículo de ciências na escola primária norteamericana em uma perspectiva funcional. In: ENCONTRO NACIONAL DE PESQUISA EM EDUCAÇÃo EM CIÊnCIAS, 7., 2000, Florianópolis. Atas... Florianópolis: Associação Brasileira de Pesquisa em Educação em Ciências, 2000. p. 1-10. 121766940.20 Disponível <http://posgrad.fae.ufmg.br/posgrad/viienpec/pdfs/1178.pdf>. Acesso em: 2 abr. 2017.

SASSERON, L. H.; CARVALHO, A. M. P. Almejando a alfabetização científica no ensino fundamental: a proposição e a procura de indicadores do processo. Investigações em Ensino de Ciências, Porto Alegre, v. 13, n. 3, p. 333-352, 2008. Disponível em: <http://www.if.ufrgs.br/ienci/artigos/Artigo_ID199/v13_n3_a2008.pdf>. Acesso em: 07 nov. 2019

SHIROMA, E. O. et al. Política educacional. Rio de Janeiro: Lamparina, 2007.

SILVA, Bo. V. da C. et al. Um estudo exploratório sobre a inserção da natureza da ciência na sala de aula em revistas da área de ensino de ciências. Holos, [s. l.], v. 7, p. 266-280, nov. 2016. ISSN 1807-1600. Disponível em: <http://www2.ifrn.edu.br/ojs/index.php/ HOLOS/article/view/3138>. Acesso em: 22 maio 2017.

SILVEIRA, F. L. da; OSTERMANN, F. A insustentabilidade da proposta indutivista de "descobrir a lei a partir de resultados experimentais". Caderno Brasileiro de Ensino de Física, Florianópolis, v. 19, p. 7-27, 2002.

SORIANO, A. et al. Aspecto do ensino de química na escola média no nordeste brasileiro. Revista Iberoamericana de Educación Química, México, DF, v. 1, n. 5, p 5-8, 1974.

TAILÂNDIA. Declaração Mundial sobre Educação para Todos. UNESCO, 1990.

TENREIRO-VIEIRA, C.; MARQUES VIEIRA, R. Educação em ciências e matemática com orientação CTS promotora do pensamento crítico. Revista Iberoamericana de Ciencia, Tecnología y SociedadCTS, Buenos Aires, v. 11, n. 33, p. 143-159, 2016. Disponível em: <http://www.revistacts.net/files/Volumen_11_Numero_33/VieiraEDITADO.pdf>. Acesso em: 2 abr. 2017.

VIEIRA, N. M. Educação formal de Ciências: prioridade para o cientista ou para o cidadão? Revista Pedagógica, Chapecó, v. 15, p. 183-194, $2014 . \quad$ Disponível em: <http://bell.unochapeco.edu.br/revistas/index.php/pedagogica/article/view/364>. Acesso em: 2 abr. 2017. 
VIEIRA, S. L.; FARIAS, I. M. S de. História da educação no Ceará: sobre promessas, fatos e feitos. Fortaleza: Edições Demócrito Rocha, 2002.

Submissão: 19/10/2020

Aceito: 21/12/2020

\begin{abstract}
' As bases de dados foram escolhidas devido ao acesso, à disponibilidade, à importância para a área acadêmica e por se tratarem de gêneros acadêmicos distintos, ou seja, teses, dissertações, artigos, resumos expandidos em eventos. Para maiores informações: BDTD (Dísponível em: http://bdtd.ibict.br/vufind/ ), Abrapec (Disponível em: http://abrapecnet.org.br/wordpress/pt/atas-dos-enpecs/ ) e Portal dos Periódicos Capes (Disponível em: http://www.periodicos.capes.gov.br/ ).

ii Operadores booleanos ou Operadores Lógicos booleanos são caracteres inseridos entre os descritores que fazem combinações como operadores lógicos, informando ao sistema que tipa de busca está sendo desejada. Os seguintes operadores booleanos estão disponíveis: AND,,+ OR, NOT e -. Maiores informações no site da Biblioteca Digital de Teses e Dissertações há uma aba de Ajuda com operadores de busca.
\end{abstract}

iii Em 2020, a Rússia anuncia o desenvolvimento de uma possível vacina contra a Covid-19, chamada de Sputink$V$. Seria, o momento pandêmico, o novo momento de disputa tecnológica que propulsionará o ensino de ciências? Sem dúvida, não foi nosso objetivo desenvolver nesse trabalho respostas para essa questão, mas contribuir, a partir da história da Educação Científica, com possíveis novas questões e caminhos para a área de pesquisa.

iv Santos (2000) discute ainda que para cada área havia um projeto distinto, os quais alguns vieram posteriormente para o Brasil traduzidos, por exemplo, pelas editoras Abril e UnB, como o Biology Science Study Committee (BSSC) destinado ao ensino de Biologia, para a Física tinham o Physical Science Study Committee (PSSC) e o Harvard Physics Project (HPP), para Química haviam ainda o Chemical Bond Approach (CBA) e o Chemical Education Material Study (Chems), o que foi denominado na literatura especializada de "sopa alfabética".

${ }^{\vee}$ Os termos Letramento Científico e Alfabetização científica apresentam, ainda, muitas pluralidades semânticas na literatura da área. Alguns autores discutem essa questão como uma problemática de tradução entre português de Portugal e português do Brasil. Sugerimos, para maiores esclarecimentos da causa, a pesquisa apresentada por Sasseron e Carvalho (2008). 